\title{
Exploring the Rational Designing of Protein Ligand Binding for Mouth Ulcer from Methanolic Extract of Olax psittacorum
}

\author{
Choudhury Priyabati ${ }^{1, \star}$, Adhikari Lopamudra ${ }^{2}$, Pattanaik Sovan ${ }^{2}$ \\ ${ }^{1}$ School of Pharmacy, ARKA JAIN University, Jharkhand, INDIA. \\ 'Department of Pharmaceutical Analysis and Quality Assurance, School of Pharmaceutical Sciences, Siksha 'O' Anusandhan \\ (Deemed to be University), Kalinga Nagar, Bhubaneswar, Odisha, INDIA.
}

\begin{abstract}
Background: Olax psittacorum, a flowering plant grown in open forests, is consumed by the locals as dietary sources. Aim: This study was designed to check the phytochemical screening, antioxidant activity, antimicrobial studies and Chorioallantoic Membrane (CAM) study in the methanolic extract of Olax psittacorum. Further, in silico docking study was performed on the basis of GC-MS report of the methanolic extract. Methods: Antimicrobial activity was tested against five bacterial strains Escherichia coli, Salmonella typhi, Pseudomonas aeruginosa, Shigella flexneri, Straphylococcus aureus. In silico docking study was done by two software, Patchdock followed by Firedock and HEX 8.0.0. to find the best fit receptor ligand docked structure. Results: Methanolic extract of Olax psittacorum has exhibited appreciable antioxidant activity. The study showed that the methanolic extract of Olax psittacorum $(10 \mathrm{mg} / \mathrm{ml})$ with DMSO shows very less activity against Escherichia coli, Salmonella typhi and did not show any activity in Pseudomonas aeruginosa, Shigella flexneri, Staphylococcus aureus. The result of the CAM study showed that the extract has good antiangiogenic activity. The methanolic extract containing phytoligand 1,2 -Benzenedicarboxylic acid, butyl octyl ester against salivary peroxidase shows maximum Global energy of $-69.40 \mathrm{kcal} / \mathrm{mol}$. Conclusion: This study attempted a new dimension for establishing phytochemicals present over methanolic extract of Olax psittacorum which may be useful for mouth ulcer prevention. Science and technology are growing faster to make up things much better but is still lagging with some issues. In vitro and in vivo models help us in determining many facts about plant and its constituent but still it also has many drawbacks. In an intention to overcome the drawbacks an economic and moreover not harming any life creature CAM studies were performed.
\end{abstract}

Key words: Protein-ligand binding, Toxicity, Antioxidant study, Activity study, Methanolic extract.

\section{INTRODUCTION}

An ulcer is an exposed sore in the lining of the epithelial cell or deep injury in a specific region of the body or organ causing its degradation and disturbing the usual physiology of the affected organ. ${ }^{1}$ Mouth ulcers are development of small painful sores on the inside lining of the mouth. They grow on the inside of the cheeks, lips and underneath of the tongue. Destruction of the inner lining of the mouth can be caused by various factors, leading to a mouth ulcer. But sometimes the cause of a mouth ulcer is unknown. Oral ulceration may occur due to viral infections or disruption in the function of gastrointestinal, haematological, immunological and dermatological systems. ${ }^{2}$ The oral mucosa is coated by saliva, shielding it leads to suffering during eating, swallowing and speaking. In people with reduced saliva, mouth soreness is very common.

The human salivary peroxidase system (SPS) is one of the non-immunoglobulin
Submission Date: 02-06-2020; Revision Date: 02-12-2020; Accepted Date: 09-02-2021

DOI: 10.5530/ijper.55.2.83 Correspondence: Dr. Lopamudra Adhikari School of Pharmaceutical Sciences, Siksha 'O' Anusandhan (Deemed to be University), Kalinga Nagar, Bhubaneswar-751003,

Odisha, INDIA.

Phone no: +91 9776354163

Email id: lopamudraadhikari@ soa.ac.in

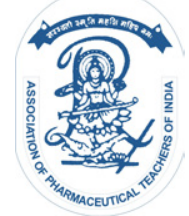

www.ijper.org 
defence factors which regulate the quantity and species distribution of oral micro-organism that helps in the maintenance of decent oral health. It prevents toxic build-ups of hydrogen peroxide $\left(\mathrm{H}_{2} \mathrm{O}_{2}\right)$ and deactivates many cancer-causing and mutagenic compounds. ${ }^{3}$ Under normal conditions a physiological balance exists, but in case of mucosal injury the balance between the aggressive factor and the defensive mechanism is disrupted thus leading to formation of mouth ulcer.

From the beginning of human history, the importance of medicinal plant was known and it has been used in drug development and for curing different diseases. Researchers have always been fascinated by the traditional folk treatment consuming wild plants to exploration for new medication to develop fit life for human. ${ }^{4}$

Olax psittacorum a flowering plant grown in open forests, belonging to the family Olacaceae, found throughout the topical region of the world. The plant contains saponin, which when given orally to mice shows anti-inflammatory properties and decreases oedema. Olaxoside also shows laxative action. The leaf of Olax psittacorum also shows antioxidant activity. ${ }^{5}$

\section{MATERIALS AND METHODS}

\section{Plant collection}

Fresh leaves of Olax psittacorum were collected from Regional Plant Research Centre (RPRC), Odisha. The freshly collected leaves were washed, dried in shade for about 7 days and then grinded to form coarsely grounded powder. Authenticated field number RMOP-1

\section{Preparation of plant extract}

The dry powder sample were placed in the glass Soxhlet and successive extraction using Petroleum ether followed by methanol $(600 \mathrm{ml})$ for 2 days was carried out for total extraction process. At the end the plant methanolic extract was filtered using Whatman filter paper and was evaporated to obtain a concentrated leaf methanolic extract (LME), which is a greenish black sticky mass. Percentage yield of the extract was calculated.

Amount of grounded materials introduced for soxhlation

$$
\% \text { Yield }=\frac{\text { introduced for soxhlation }}{\text { Amount of concentrated extract }} \times 100
$$

\section{Phytochemical screening}

Using standard qualitative method screening for major phytochemical constituents was carried out. ${ }^{6}$ Phytochemical screening test was carried out from freshly prepared methanolic extract of the leaves for alkaloids, glycosides, carbohydrates, tannins, saponins, flavonoid, proteins steroids, oils, fats etc.

\section{In vitro antioxidant assay}

For determining the in vitro antioxidant capacity, two most acceptable method DPPH (2, 2'-diphenyl1 picrylhydrazyl $)$ and ABTS (2, 2'-azinobis 3-ethylbenzthiozoline- 6 sulphonic acid) were carried out separately. ${ }^{7}$ Extract solution of $1 \mathrm{mg} / \mathrm{ml}$ was prepared using methanol and from it further dilutions of 50,100, 200, 300, 400, $500 \mu \mathrm{g} / \mathrm{ml}$ was obtained.

\section{DPPH radical scavenging activity}

$1 \mathrm{ml}$ from each of the dilution was taken into different test tubes to which $3 \mathrm{ml}$ DPPH solution (methanolic) was added to each of the test tube. The mixture was shaken and left in dark at room temperature. Absorbance was measured at $517 \mathrm{~nm}$ after 30 min against a blank. Ascorbic acid was taken as the positive control. The percentage of inhibition of DPPH (I \%) was calculated by means of the following equation:

Inhibition $(\%)=\left[\left(\mathrm{A}_{\text {control }}-\mathrm{A}_{\text {test }}\right) / \mathrm{A}_{\text {control }}\right] \times 100$

Where, $\mathrm{A}_{\text {control }}=$ the absorbance of ABTS solution without any sample

$\mathrm{A}_{\text {test }}=$ the absorbance of ABTS solution with sample in different concentration

\section{ABTS+ Scavenging Activity}

A dark coloured greenish solution was obtained when the mixture of ABTS $(7.0 \mathrm{mM})$ and Potassium persulphate $(140 \mathrm{mM})$ was kept in the dark for $16 \mathrm{~h}$ at ambient temperature. The ABTS solution was diluted to obtain an absorbance of $0.700 \pm 0.05$ at $754 \mathrm{~nm}$ with methanol. Then $3 \mathrm{ml}$ of ABTS was added to $1 \mathrm{ml}$ of the sample concentration $(50-500 \mu \mathrm{g} / \mathrm{ml})$. After 30 min the absorbance was taken at $754 \mathrm{~nm}$. The ABTS+ scavenging activity was calculated by means of the following equation:

Inhibition $(\%)=\left[\left(A_{\text {control }}-A_{\text {test }}\right) / A_{\text {control }}\right] \times 100$

Where, $\mathrm{A}_{\text {control }}=$ the absorbance of ABTS solution without any sample

$A_{\text {test }}=$ the absorbance of ABTS solution with sample in different concentration

\section{Antimicrobial Study}

\section{Bacterial strains}

The antibacterial activity of the methanolic extracts was evaluated using five bacterial strains. Four strains of gram-negative bacteria (Escherichia coli, Pseudomonas aeruginosa, Salmonella typhi, Shigellaf lexneri) and one grampositive bacteria (Straphylococcus aureus). The bacterial 
strains were provided by RMRC (Regional Medical Research Centre), Bhubaneswar.

\section{Inoculums preparation}

Each bacterial strain was sub cultured overnight at $37^{\circ} \mathrm{C}$ in Nutrient Agar media or Lysogeny Agar media. The bacterial growth was harvested using $1 \mathrm{ml}$ of sterile saline water.

\section{Well diffusion method for the determination of zone of inhibition}

Using well diffusion method the antibacterial activity of the methanolic extract of Olax psittacorum was performed. Mueller-Hilton agar $(15 \mathrm{ml})$ medium was poured in clean sterilized petri-plate and allowed to cool and solidify. ${ }^{6}$ With the help of cotton swab broth of bacterial strain $(100 \mu l)$ was pipetted out and uniformly spread over the medium dried properly. Solutions of the extracts $(10 \mathrm{mg} / \mathrm{ml})$ in dimethyl sulphoxide (DMSO) were prepared. Hundred microliters of plant extract solution were added to the wells $(6 \mathrm{~mm})$ which were created by tunnelling into the agar medium. The petriplates were incubated at $37^{\circ} \mathrm{C}$ for $24 \mathrm{~h}$.

\section{In silico biomodelling and docking study}

\section{Preparation of receptor}

\section{Sequence retrieval of salivary peroxidase}

The protein sequence of Human Salivary peroxidase, Accession: AAC50717.1 was retrieved from the NCBI database and the FASTA sequence and 712 amino acid protein is used for our study.

The accession by using PSI-BLAST >AAC50717.1 salivary peroxidase [Homo sapiens]

MRVLLHLPALLASLILLQAAASTTRAQTTRTSAI SDTVSQAKVQVNKAFLDSRTRLKTAMSSETPTS RQLSEYLKHAKGRTRTAIRNGQVWEESLKRLR QKASLTNVTDPSLDLTSLSLEVGCGAPAPVVRC DPCSPYRTITGDCNNRRKPALGAANRALARWL PAEYEDGLSLPFGWTPGKTRNGFPLPLAREVSN KIVGYLNEEGVLDQNRSLLFMQWGQIVDHDL DFAPDTELGSSEYSKAQCDEYCIQGDNCFPIMF PPNDPKAGTQGKCMPFFRAGFVCPTPPYKSLAR EQINALTSFLDASFVYSSEPSLASRLRNLSSPLGL MAVNQEVSDHGLPYLPYDSKKPSPCEFINTTAR VPCFLAGDSRASEHILLATSHTLFLREHNRLARE LKRLNPQWDGEKLYQEARKILGAFVQIITFRDY LPILLGDHMQKWIPPYQGYSESVDPRISNVFTFA FRFGHLEVPSSMFRLDENYQPWGPEPELPLHTL FFNTWRMVKDGGIDPLVRGLLAKKSKLMKQN
KMMTGELRNKLFQPTHRIHGFDLAAINTQRCR DHGQPGYNSWRAFCDLSQPQTLEELNTVLKSK MLAKKLLGLYGTPDNIDIWIGAIAEPLVERGRV GPLLACLLGKQFQQIRDGDRFWWENPGVFTN EQKDSLQKMSFSRLVCDNTRITKVPRDPFWANS YPYDFVDCSAIDKLDLSPWASVKN

\section{Screening for best homologous templates}

Homology modelling approach was used for predicting 3-Dstructure of salivary peroxidase which is based on pre-determined homologous template. In the retrieval of sequence of salivary peroxidase from NCBI database resulting query sequence with the accession AAC50717.1 were subjected by using PSI-BLAST. After analysis the PSI-BLAST result, the best protein was selected based on the similarity, identity and query across Protein Data Bank.

By using 4 selected templates (test sequence) homology modelling was carried out. The generated salivary peroxidase models were further validated by using MORDRED RAMPAGE.

The in silico comparative modelling of the salivary peroxidase protein was performed by the MODELLER 9.1.9. The best homology was created by taking files of query sequence, test sequence and script as directed in the MODELLER. The modelled structure was further validated, the best optimised structure was selected on the basis of more number of residue in favoured region and less in outlier region.

\section{Preparation of ligands}

The selection of ligand molecules is based on the GC-MS result of the methanolic extraction of in Olax psittacorum. ${ }^{8}$ The ligands were 9-Octadecenoic acid (Z)-, methyl ester[1(A)], Campestanol [1(B)], Phytol [1(C)], Cyclohexene,1-methyl-4-(1-methylethylidene)[1(D)], Benzoic acid, 2,6-bis[(trimethylsilyl)oxy]-,trimethylsilyl ester[1(E)], Methyl salicylate [1(F)], Hexadecanoic acid, methyl ester $[1(\mathrm{G})], 1$,2-Benzenedicarboxylic acid, butyl octyl ester[1(H)], 11-Octadecenoic acid, methyl ester [1(I)], Beta-Sitosterol[1(J)], 13-Docosenamide,(Z) $[1(\mathrm{~K})]$, Phthalic acid, di(2-propylpentyl) ester[1(L)], Ligand molecules were designed by using ACD/ ChemSketch followed by optimisation. Then the file is stored in MDL Molfiles (V2000) (*.mol). The .mol file of ligand was converted to pdb file using Open Babel GUI. The QSAR properties study of selected ligands was done by SWISS ADME SERVER from which the Formula, Molecular Weight, Hydrogen Bond Acceptor, Hydrogen Bond Donor, Log $P_{\mathrm{o} / \mathrm{w},}$ Pharmacokinetics, Druglikeneess, Bioavailability score. 
Molecular Docking by using patch dock and fire dock

The server Patch dock mostly served for molecular docking resulting generation of transformation file followed with generation of binding energy by using Fire Dock. This includes a variety of energy van der Waals interactions, desolvation energy (atomic contact energy, ACE), partial electrostatics, p-stacking and aliphatic interactions, hydrogen and disulfide bonds rotamer's probabilities and more.

\section{Molecular Docking by using HEX}

The docking studies was done by using Hex 8.0.0, which was performed by FFT Steric Scan SP Fourier Transform, FFT Final Search and MM Refinement. The resultant $\mathrm{E}$ total (binding energy) was compared with the result of Patchdock and Firedock. The outcome of the result of the ligand that produced the best ETotal, minimum energy, was selected as the best inhibitor.

\section{Chorioallantoic membrane (CAM) assay}

5 days old fertile chicken eggs which were incubated at $37^{\circ} \mathrm{C}$ were obtained from Central Poultry Development Organization (E.R.), Bhubaneswar.'

\section{Candling experiment}

This study was mainly done to check the viability of the eggs before the experiment. Using a flashlight the position of the developing embryo was checked and the dead and undeveloped embryo was discarded. To remove dirt and contaminants the eggs were cleaned with $70 \%$ ethanol. The whole assay procedure was performed under laminar air flow.

\section{Preparation of doses}

The extract was dissolved in DMSO and a concentration of $10 \mathrm{mg} / \mathrm{ml}$ standard stock solution was prepared. DMSO was used as negative control. Filter paper of $3 \mathrm{~mm}$ diameter was cut and sterilised properly. From the standard stock solution, different volume of the solution was applied drop wise onto individual sterilised

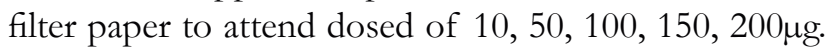
$100 \mu \mathrm{l}$ of DMSO was used as negative control.

\section{Assay method}

The eggs were broken with high attention using forceps from the narrow side of the eggs. $1 \mathrm{~cm}$ square window was made so that the CAM gets exposed and the dried filter paper containing the desired concentration of the sample can be implanted. Before and while dosing the photographs was taken. The opening of the eggs were then closed with cellophane tape and kept in incubator at $37^{\circ} \mathrm{C}$ for about 4 hrs. Photographs were taken at 4 hours after removing the filter paper caring the extract. The image of the same CAM (before and after treatment) was compared and the antiangiogenic effect was quantified. A semi quantitative score system with scale of 0-2 was used. The degree of antiangiogenic effect was recorded blindly by ten observers. The average score was calculated for every test sample.

\section{RESULTS AND DISCUSSION}

Among the several phytochemical constituents, many of which are recognised to be biologically active and are responsible for revealing diverse pharmacological activities. Screening of the phytochemicals gives wide ranging ideas regarding the nature of the compounds present in the plant which is important for exploring any medicinal plant. Introductory phytochemicals analysis on methanolic leaf extract of Olax psittacorum was carried out and their results were presented in Table 1.

The major secondary metabolites were present in the extracts such as flavonoid, tannin, Terpenoids, steroid and carbohydrate, saponin, tannins, phenols, Proteins and amino acid Fixed Oils and Fats. On the other hand, alkaloids and glycosides are absent in the methanolic extract.

The leaf extract of Olax psittacorum along with the reference standards were studied by DPPH radical scavenging activity assay and ABTS scavenging activity for in vitro Antioxidant activity. The scavenging effect of leaves extracts on the DPPH free radicals as well as ABTS were expressed as $\%$ inhibition and they were compared with standard antioxidant ascorbic acid. ${ }^{6}$ With the increase in concentration, the percentage of scavenging in both DPPH and ABTS increases. The concentration at which inhibition shows $50 \%$ of

\begin{tabular}{|c|c|c|}
\hline \multicolumn{3}{|c|}{ Table 1: Phytochemical Screening. } \\
\hline $\begin{array}{c}\text { SI. } \\
\text { No }\end{array}$ & Phytoconstituents & LME \\
\hline 1 & Alkaloid & - \\
\hline 2 & Carbohydrates and reducing \\
sugar & + \\
\hline 3 & Flavonoids & + \\
\hline 4 & Glycoside & - \\
\hline 5 & Proteins and amino acids & + \\
\hline 6 & Saponin & + \\
\hline 7 & Steroids and Terpenoids & + \\
\hline 8 & Tannin & + \\
\hline 9 & Phenols & + \\
\hline 10 & Fixed Oils and Fats & + \\
\hline
\end{tabular}


scavenging activity is $400 \mu \mathrm{g} / \mathrm{ml}$ and $200 \mu \mathrm{g} / \mathrm{ml}$ for DPPH and ABTS respectively (Figure 1)

Staphylococcus aureus, a gram positive bacterium is considered as pathogen whose major site of colonization in human body is anterior nares. $S$. aureus cause infection that affect blood stream, skin, soft tissue and lower respiratory tracts. $S$. aureusis one of the major causes of hospital-acquired and community acquire infections which results into serious problems. E. coli, a gram negative bacteria is commonly found in the lower intestine of warm-blooded organisms. The pathogenic E. coli causes serious food poisoning in human. Pseudomonas aeruginosa also causes nosocomial infections. ${ }^{5}$ Methanolic extract of Olax psittacorum was evaluated for their antimicrobial activity against certain Gram negative and Gram positive bacteria, which was regarded as human pathogenic microorganism (Figure 2).

The study shows that the methanolic extract of Olax psittacorum in the concentration of $10 \mathrm{mg} / \mathrm{ml}$ with DMSO shows very less activity against Escherichia coli, Salmonella typhi, and did not show any activity in Pseudomonas aeruginosa, Shigella flexneri, Straphylococcus aureus (Table 2).
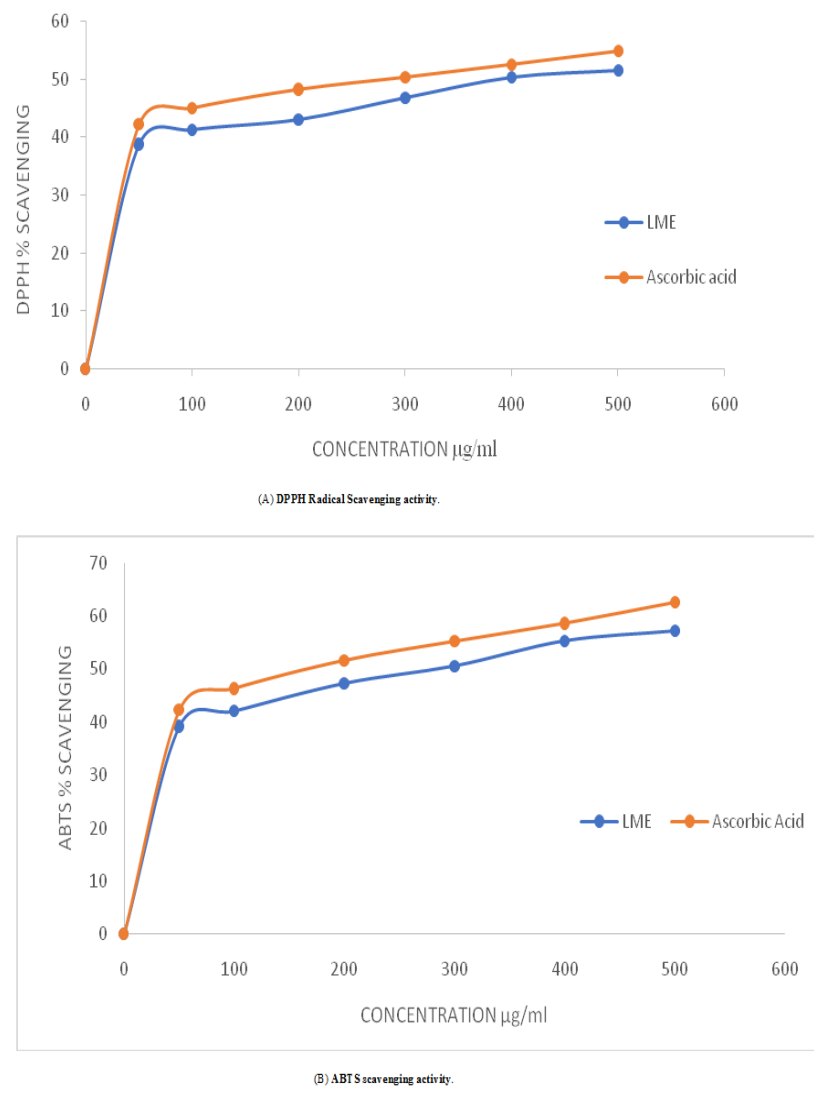

Figure 1: Anti-oxidant activity of LME, concentrations ranging from $50-500 \mu \mathrm{g} / \mathrm{ml}$.
The structure of the receptor, salivary peroxidase was retrieved from the NCBI database which is a 712 amino acid protein. The PSI- BLAST result were analysed across Protein Data Bank and the 4 selected based on the percentage of identity, similarity and query coverage. Accession no. with chain are as follows 2IKC A, 3R5Q A, 2E9E A, 5B72 A and \% of identity are $84.87 \%, 84,71 \%, 84.20 \%, 85.38 \% .{ }^{10}$ Homology Modelling for Receptor was done using Modeller 9.1.9. Using MORDRED RAMPAGE the 5 hypothetical modelled was evaluated to get the Ramachandran plot. From the 5 Ramachandran plot obtained pdb id: qseq1 B999004 showed the best acceptable result with 91.7\% of residues in favoured region, 5.2\%, allowed region and $3.1 \%$ outlier regions if compared with other plots, qseq1 B9990001, 90.6\%, 6.6\%, 2.8\%of residues in favoured, allowed outlier regions respectively, qseq1 B9990002, 90.1\%, 6.9\%, 3.0\% of residues in favoured, allowed, outlier regions respectively. qseq1 B9990003, $89.7 \%, 6.5 \%$ and $3.8 \%$ of residues in favoured, allowed, out lier regions respectively. qseq1 B9990005, 91.3\%, $5.9 \%, 2.8 \%$ of residues in favoured, allowed, outlier

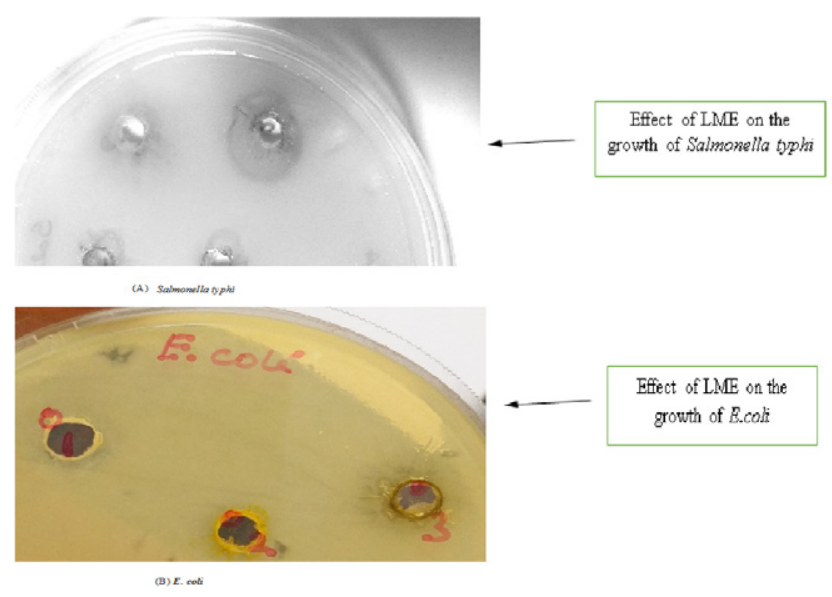

Figure 2: Anti Bacterial Assay Result Showing the Inhibition cause by $10 \mathrm{mg} / \mathrm{ml}$ solution in DMSO of the LME.

\begin{tabular}{|c|c|c|c|}
\hline \multicolumn{4}{|c|}{ Table 2: Anti-bacterial activity of LME. } \\
\hline $\begin{array}{c}\text { SI. } \\
\text { no }\end{array}$ & \multicolumn{2}{|c|}{ Test organism } & $\begin{array}{c}\text { Zone of } \\
\text { inhibition } \\
\text { (mm) }\end{array}$ \\
\hline 1 & Salmonella typhi & $\begin{array}{c}\text { Gram } \\
\text { negative }\end{array}$ & $2.35 \pm 0.58$ \\
\hline 2 & Escherichia coli & $\begin{array}{c}\text { Gram } \\
\text { negative }\end{array}$ & $0.53 \pm 0.58$ \\
\hline 3 & $\begin{array}{c}\text { Pseudomonas } \\
\text { aeruginosa }\end{array}$ & $\begin{array}{c}\text { Gram } \\
\text { negative }\end{array}$ & 0 \\
\hline 4 & Shigella flexneri & $\begin{array}{c}\text { Gram } \\
\text { negative }\end{array}$ & 0 \\
\hline 5 & Staphylococcus aureus & $\begin{array}{c}\text { Gram } \\
\text { positive }\end{array}$ & 0 \\
\hline
\end{tabular}


regions respectively. ${ }^{11}$ The ligands were selected from the GC-MS results from the available literature. QSAR properties of the selected ligands were studied for knowing their formula, molecular weight, hydrogen bond acceptor, hydrogen bond donor (Table 3). Docking of the receptor and ligand was done by two software, Patch dock followed by Firedock and HEX 8.0.0. From the result of the Firedock, 1,2-Benzenedicarboxylic acid, butyl octyl ester $[1(\mathrm{H})]$ shows maximum Global energy of $-69.40 \mathrm{kcal} / \mathrm{mol}$ when compared with the other ligands having -29.88 to $-65.80 \mathrm{kcal} / \mathrm{mol}$ (Table 4). The visualization of modelled receptor was done through UCSF CHIMERA (Figure 3).

The active residues was identified as ALA 159, GLU 295, ILE 15, ARG162, LEU 160, PRO 165, ALA 166,

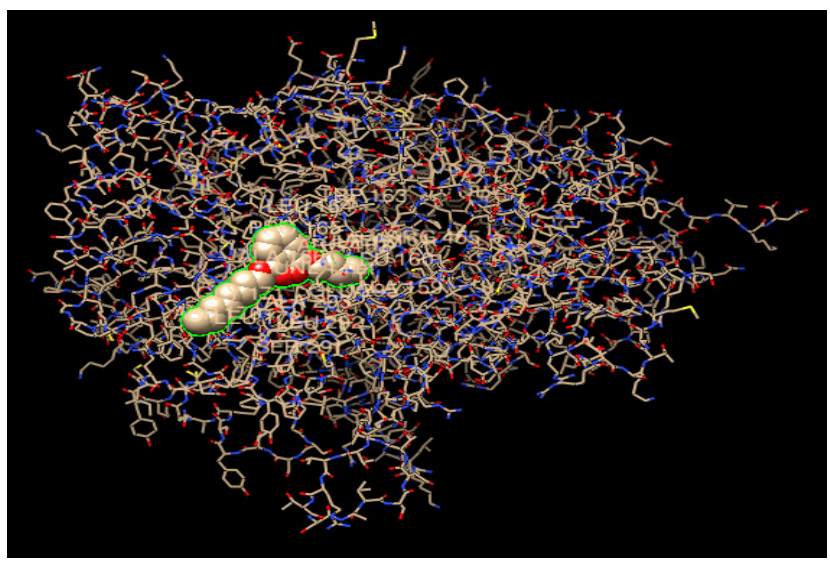

Figure 3: Molecular docking result of salivary peroxidase with 1, 2-Benzenedicarboxylic acid, butyl octyl ester using Patchdock and Firedock (All atoms Structure).

Table 3: Summary of Mean Physical Chemical Distribution of the Selected Ligands.

\begin{tabular}{|c|c|c|c|c|c|c|c|c|c|}
\hline SI.no & $\begin{array}{c}\text { Ligand } \\
\text { Code }\end{array}$ & Formula & M.W & $\begin{array}{c}\text { HB } \\
\text { Acceptor }\end{array}$ & $\begin{array}{c}\text { HB } \\
\text { Donar }\end{array}$ & $\begin{array}{c}\text { Log } \\
\boldsymbol{P}_{\text {o/w }}\end{array}$ & Pharmacokinetics & Druglikeneess & $\begin{array}{c}\text { Bioavailability } \\
\text { score }\end{array}$ \\
\hline 1 & $1(\mathrm{~A})$ & $\mathrm{C}_{19} \mathrm{H}_{36} \mathrm{O}_{2}$ & $296.49 \mathrm{~g} / \mathrm{mol}$ & 2 & 0 & 5.95 & High & Yes & 0.55 \\
\hline 2 & $1(\mathrm{~B})$ & $\mathrm{C}_{28} \mathrm{H}_{50} \mathrm{O}$ & $402.70 \mathrm{~g} / \mathrm{mol}$ & 1 & 1 & 7.14 & Low & Yes & 0.55 \\
\hline 3 & $1(\mathrm{C})$ & $\mathrm{C}_{21} \mathrm{H}_{42}$ & $294.56 \mathrm{~g} / \mathrm{mol}$ & $0 \mathrm{z}$ & 0 & 7.63 & Low & Yes & 0.55 \\
\hline 4 & $1(\mathrm{D})$ & $\mathrm{C}_{10} \mathrm{H}_{16}$ & $136.23 \mathrm{~g} / \mathrm{mol}$ & 0 & 0 & 3.40 & Low & Yes & 0.55 \\
\hline 5 & $1(\mathrm{E})$ & $\mathrm{C}_{7} \mathrm{H}_{12} \mathrm{O}_{4} \mathrm{Si}_{3}$ & $244.42 \mathrm{~g} / \mathrm{mol}$ & 4 & 0 & -0.07 & Low & Yes & 0.55 \\
\hline 6 & $1(\mathrm{~F})$ & $\mathrm{C}_{8} \mathrm{H}_{8} \mathrm{O}_{3}$ & $152.15 \mathrm{~g} / \mathrm{mol}$ & 3 & 1 & 1.66 & High & Yes & 0.55 \\
\hline 7 & $1(\mathrm{G})$ & $\mathrm{C}_{17} \mathrm{H}_{34} \mathrm{O}_{2}$ & $270.45 \mathrm{~g} / \mathrm{mol}$ & 2 & 0 & 5.54 & High & Yes & 0.55 \\
\hline 8 & $1(\mathrm{H})$ & $\mathrm{C}_{20} \mathrm{H}_{30} \mathrm{O}_{4}$ & $334.45 \mathrm{~g} / \mathrm{mol}$ & 4 & 0 & 5.09 & High & Yes & 0.55 \\
\hline 9 & $1(\mathrm{I})$ & $\mathrm{C}_{21} \mathrm{H}_{42}$ & $294.56 \mathrm{~g} / \mathrm{mol}$ & 0 & 0 & 7.63 & Low & Yes & 0.55 \\
\hline 10 & $1(\mathrm{~J})$ & $\mathrm{C}_{29} \mathrm{H}_{50} \mathrm{O}$ & $414.71 \mathrm{~g} / \mathrm{mol}$ & 1 & 1 & 7.20 & Low & Yes & 0.55 \\
\hline 11 & $1(\mathrm{~K})$ & $\mathrm{C}_{22} \mathrm{H}_{45} \mathrm{NO}$ & $339.60 \mathrm{~g} / \mathrm{mol}$ & 1 & 1 & 7.02 & Low & Yes & 0.55 \\
\hline 12 & $1(\mathrm{~L})$ & $\mathrm{C}_{24} \mathrm{H}_{38} \mathrm{O}_{4}$ & $390.56 \mathrm{~g} / \mathrm{mol}$ & 4 & 0 & 6.16 & High & Yes & 0.55 \\
\hline
\end{tabular}

\begin{tabular}{|c|c|c|c|c|c|c|}
\hline \multicolumn{7}{|c|}{ Table 4: Docking Score Using FIREDOCK and HEX. } \\
\hline SI.no & Ligand code & \multicolumn{3}{|c|}{ Fire dock } & \multicolumn{2}{c|}{ Hex } \\
\hline & & GE & VF & RF & Etotal \\
\hline 1. & $1(\mathrm{~A})$ & -52.98 & -21.79 & 6.35 & -16.09 & -289.15 \\
\hline 2. & $1(\mathrm{~B})$ & -65.80 & -28.73 & 3.68 & -16.20 & -321.68 \\
\hline 3. & $1(\mathrm{C})$ & -45.42 & -22.17 & 14.93 & -15.48 & -275.61 \\
\hline 4. & $1(\mathrm{D})$ & -29.88 & -11.34 & 3.12 & -10.18 & -178.38 \\
\hline 5. & $1(\mathrm{E})$ & -39.58 & -11.71 & 5.00 & -16.83 & -206.30 \\
\hline 6. & $1(\mathrm{~F})$ & -30.55 & -11.95 & 1.64 & -9.08 & -179.20 \\
\hline 7. & $1(\mathrm{G})$ & -45.73 & -20.02 & 5.01 & -12.67 & -304.45 \\
\hline 8. & $1(\mathrm{H})$ & -69.40 & -26.61 & 3.46 & -20.28 & -309.65 \\
\hline 9. & $1(\mathrm{I})$ & -53.43 & -21.05 & 5.29 & -16.55 & -304.94 \\
\hline 10. & $1(\mathrm{~J})$ & -64.46 & -26.68 & 10.71 & -21.50 & -298.34 \\
\hline 11. & $1(\mathrm{~K})$ & -62.18 & -25.23 & 5.66 & -18.51 & -340.38 \\
\hline 12. & $1(\mathrm{~L})$ & -60.80 & -25.89 & 10.54 & -19.34 & -280.64 \\
\hline
\end{tabular}


ALA 293, LEU164, SER 291, ASP 170, GLY 171, LEU 172, LEU 292, ARG 455, TRP 163. Using HEX 8.0.0, the Etotal of 1,2-Benzenedicarboxylic acid, butyl octyl ester was -309.65 .

CAM assay is widely used for proangiogenic and antiangiogenic evaluation of different materials. Angiogenesis refers to the development of new blood vessels from the predating vasculature, whereas antiangiogenesis refers to the inhibition of growth or death of the blood vessels. Both angiogenesis and anti- angiogenesis have their merits as well as demerits. Angiogenesis plays an important role in growth and metastasis of tumours and thus, cancer. From day $4^{\text {th }}$ to $10^{\text {th }}$ day, the allantoic vesicle enlarges rapidly and mesodermal layer of the allantois fuses with mesodermal layer of chorion to form Chorioallantoic membrane (CAM). ${ }^{10}$ Neither growth nor any inhibition was seen with the blank controls. Comparison of $0 \mathrm{~h}$ pictures in each case is done with $4 \mathrm{~h}$ pictures to find the changes (Figure 4).

Inhibition of growth of blood vessels was seen in $\mathrm{LME}$ at dose $100 \mu \mathrm{g} / \mathrm{ml}$ and $150 \mu \mathrm{g} / \mathrm{ml}$. The degree
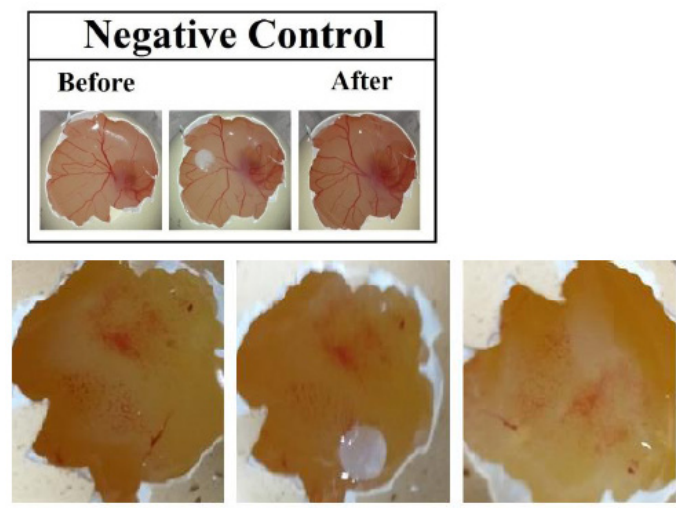

$100 \mu \mathrm{g}$
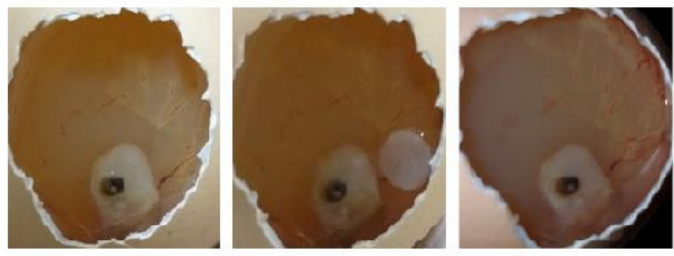

$150 \mu \mathrm{g}$

Figure 4: Images of live CAM implanted with LME different doses.

Table 5: Anti-angiogenic effects of LME of Olax psittacorum by CAM assay.

\begin{tabular}{|c|c|c|c|}
\hline Extracts & Dose $(\boldsymbol{\mu g})$ & $\begin{array}{c}\text { Average } \\
\text { score }\end{array}$ & $\begin{array}{c}\text { Anti-angiogenic } \\
\text { effect }\end{array}$ \\
\hline DMSO & $0 \mathrm{mg}$ & $0.10 \pm 1.50$ & No \\
\hline \multirow{2}{*}{ LME } & $0.10 \mathrm{mg}$ & $1.05 \pm 0.43$ & Good \\
\cline { 2 - 4 } & $0.15 \mathrm{mg}$ & $1.24 \pm 0.53$ & Good \\
\hline
\end{tabular}

of damage was evaluated by average scores calculated using the pictorial observations. This semi quantitative method was based on the observations made by five different observers having no idea of doses and extracts during observations and scores. DMSO was used as negative control in which no significant inhibition of angiogenesis was observed. The concentration of $100 \mu \mathrm{g} / \mathrm{ml}$ and $150 \mu \mathrm{g} / \mathrm{ml}$ showed good angiogenesis inhibition in LME (Table 5).

\section{CONCLUSION}

Olax psittacorum is a wild flowering plant but young shoots are consumed as dietary sources locally. From the phytochemical screening study, we came to know that this plant have maximum of the noted phytochemicals except alkaloids and glycoside. Methanolic extract of Olax psittacorum has also shown antioxidant activity. Antimicrobial studies of the extract shows that in low concentration the zone of inhibition is not prominent, but it showed a little zone of inhibition. The CAM study showed that our extract has antiangiogenic activity. From the GC-MS result, the possible phyto compounds present in the extract has been selected as ligands and in silico docking study was done to find the best fit receptor ligand docked structure. The result shows that the ligand binding study of salivary peroxidase with 1,2-Benzenedicarboxylic acid, butyl octyl ester give the best docked structure. The key residues was acknowledged as ALA 159, GLU 295, ILE 15, ARG162, LEU 160, PRO 165, ALA 166, ALA 293, LEU164, SER 291, ASP 170, GLY 171, LEU 172, LEU 292, ARG 455, TRP 163.

\section{ACKNOWLEDGEMENT}

I would like to extend my gratitude to many people who helped to bring this research fruition. I would like to thank School of Pharmaceutical Sciences, Siksha 'O' Anusandhan (Deemed to be University) for providing all the facilities needed for the experiment.

\section{CONFLICT OF INTEREST}

The authors declare that there is no conflict of interest.

\section{ABBREVIATIONS}

CAM: Chorioallantoic membrane; GC-MS: Gas chromatography-mass spectrometry; DMSO: Dimethyl sulfoxide; SPS: Salivary peroxidase System; LME: Leaf Methanolic Extract; DPPH: 2,2-diphenyl-1-picrylhydrazyl; ABTS: (2,2'-azino- 
bis(3-ethylbenzothiazoline-6-sulfonic acid)); QSAR: Quantitative structure activity relationship.

\section{REFERENCES}

1. Mehta D. Ulcer-review on types, anti-ulcer drugs, anti-ulcer medicinal plants, anti-ulcer drug market, diagnostics and current global clinical trials status. Invent Rapid Pharm Pract. 2016;2:1-8.

2. Flint S. Oral ulceration: GP guide to diagnosis and treatment. Prescriber. 2006;17(5):32-48.

3. Tenovuo J, Pruitt KM. Relationship of the Human Salivary Peroxidase System to Oral Health. J Oral Pathol. 1984;13(6):573-84.

4. Gul R, Jan SU, Faridullah S, Sherani S, Jahan N. Preliminary Phytochemical Screening, Quantitative Analysis of Alkaloids and Antioxidant Activity of Crude Plant Extracts From Ephedra Intermedia Indigenous to Balochistan. Sci World J. 2017;1-7.

5. Majumder R, Dhara M, Adhikari L. Comparative study of leaves and stem methanolic extract on antioxidant and antimicrobial activity through Quantitative evaluation of phytoconstituents. IJETMAS. 2015;3:208-16.
6. Majumder R, Dhara M, Adhikari L, Ghosh G, Pattnaik S. Evaluation of in vitro Antibacterial and Antioxidant Activity of Aqueous Extracts of Olax psittacorum. Indian J Pharm Sci. 2019;81(1):99-109.

7. Formagio AS, Volobuff CR, Santiago M, Cardoso CA, Vieira MD, Valdevina PZ. Evaluation of antioxidant activity, total flavonoids, tannins and phenolic compounds in Psychotria leaf extracts. Antioxidants. 2014;3(4):745-57.

8. Majumder R, Adhikari L, Hossain CM, Dhara M, Sahu J. Toxicological evaluation, brine shrimp lethality assay, in vivo and ex vivo antioxidant assessment followed by GC-MS study of the extracts obtained from Olax psittacorum (Lam.) Vahl. Advances in Traditional Medicine. 2020;20(3):30325.

9. Arpitha BM, Sharma N, Skariyachan S. In silico Biomodelling and Docking Studies of Claudin 1: A Rational Approach of Drug Design for Enteropathogenic E. coli Infections. Int J Pharm Sci Res. 2010;1(9):421-9.

10. Dhara M, Adhikari L, Majumder R. Chorioallantoic membrane (CAM) assay of different extracts of rhizome and inflorescence of Heliconia rostrata. Indian J Pharm Educ Res. 2018;52(4 Suppl 2):S246-51.

11. Lokman NA, Elder AS, Ricciardelli C, Oehler MK. Chick chorioallantoic membrane (CAM) assay as an in vivo model to study the effect of newly identified molecules on ovarian cancer invasion and metastasis. Int J Mol Sci. 2012;13(8):9959-70.

\section{PICTORIAL ABSTRACT}

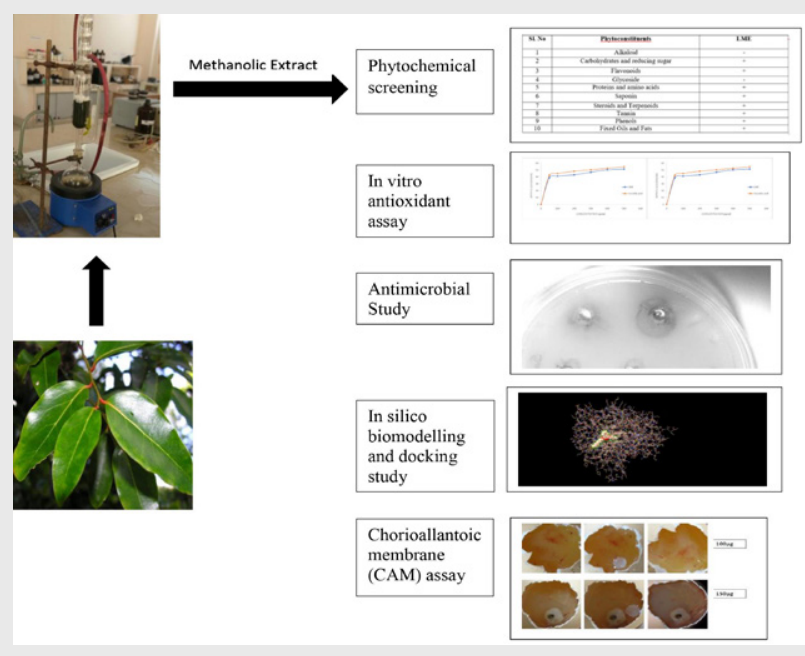

About Authors

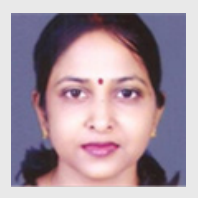

Dr. Lopamudra Adhikari: Associate Professor, Department of Pharmaceutical Analysis and Quality Assurance, School of Pharmaceutical Sciences, Siksha'O' Anusandhan (Deemed to be University), Bhubaneswar, Odisha, India.

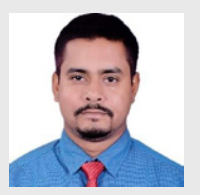

Dr. Sovan Pattnaik: Associate Professor, Department of Pharmaceutical Chemistry, School of Pharmaceutical Sciences, Siksha ' $O$ ' Anusandhan (Deemed to be University), Bhubaneswar, Odisha, India.

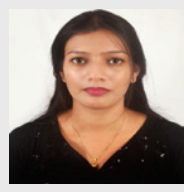

Ms. Priyabati Choudhury: Assistant Professor, Department of Pharmacy, School of Pharmacy, ARKA JAIN University, Jamshedpur, Jharkhand, India.

\section{SUMMARY}

Oral ulcers are characterised by a loss of the mucosal layer within the mouth. This loss may be acute or chronic, localised or diffuse. Fast growing Science still fall behind with some issues. This study attempted a new dimension for establishing phytochemicals present over methanolic extract of Olax psittacorum which may be useful for mouth ulcer prevention.

Cite this article: Priyabati C, Lopamudra A, Sovan P. Exploring the Rational Designing of Protein Ligand Binding for Mouth Ulcer from Methanolic Extract of Olax psittacorum Indian $\mathrm{J}$ of Pharmaceutical Education and Research. $2021 ; 55(2): 455-62$. 